\title{
Locke and Leibniz on the Balance of Reasons Markku Roinila
}

Penultimate draft. Published in in Scarafile \& Riesenfield (eds.), Philosophical Dialogue. Perspectives on theory of controversies and the ethics of communication - Explorations of Marcelo Dascal's contributions to philosophy. Springer, Dordrecht 2013, pp. 49-57.

Nouveaux essais sur l'entendement humain or New Essays on Human Understanding (NE, 1704) is a fascinating, although one-sided dialogue between John Locke (Philalethes) and Gottfried Wilhelm Leibniz (Theophilus). One of its themes, although more or less implicit in Locke's Essay Concerning Human Understanding (E, 1689) is ethics and the good life in book II, chapters xx and xxi. ${ }^{1}$

I will take a look at Locke's somewhat controversial moral philosophy, especially the question of goals of moral action and discuss Leibniz's critique of his views. To highlight professor Dascal's important work on Leibniz's conception of rationality, my main emphasis in this paper is on the different models of balancing reasons.

\section{Locke's Ethics}

Garrett Thompson sketches three kinds of moral views in Locke (Thompson 2001: 69-73). ${ }^{2}$ The first concerns natural law. He argues that universal laws which concern all human beings are knowable by reason and therefore morality is rational. This has nothing to do with innate ideas, however - Locke argues that conscience is the opinion of rightness or wrongness of one's own actions and that they are derived from education or custom (E I, iii, §8).

Locke's second moral view is related to the divine command-theory. Morality is based on God's will which is revealed to men in religion and in universal laws (E I, iii, §6) and our greatest guide in learning the laws is the Bible, besides revelation. Following God's will requires control and therefore morality requires that we can be rewarded or punished and this happens in the afterlife. Locke argues repeatedly in the Essay and the Reasonableness of Christianity that the afterlife is the only possible basis for morality, because rewards and punishments after death are the only thing great enough to give people a convincing reason to act. This is made possible by the fact that God attaches pleasure to certain kinds of acts in order to reward us for obeying his laws (E II, xxviii, §5$\S 8)$.

Closest to our everyday experience is Locke's third view in E II, xx which relates pleasure and pain with good and evil. This very Epicurean view emphasizes pleasure which to Locke signifies whatever a person desires. Like Hobbes, he does not recognize a summum bonum because people desire very different things. The problem with this view is hedonism - there seems to be no other 
moral motive than each's own pleasure $(x x i, \S 41)$ unless our education manages to provide us with good reasons to find our pleasure in common good and useful things for our community.

Locke's Balance of Pleasure and Pain

According to Locke, men desire various things and when they get them, they feel pleasure and in an opposite case, pain. The lack of some object of men's desire brings about uneasiness in them (E II, xxi). But how does the apparent hedonism and moral rationality work together in Locke's moral philosophy? When God attaches pleasure to certain objects, it is evident that at least some will strive to get them. But not everybody, is one's immanent thought. When people desire various things, it would seem that even the ones God recommends are not necessarily the ones to which everybody strives for. Locke freely admits that men can desire things which are not good for them or to the common good (II. xxi). Even if one knows exactly what to do in a given situation, she can still be weak-willed and surrender to her desires and act against one's better understanding. This is precisely why God has to attach pleasure and pain to certain acts.

Perhaps this works. When we know that eating too much leads to nausea, we try to eat moderately. However, one can argue that there are always bulimics who simply can't help themselves or those who just do not care.

But these are small potatoes. In more serious ethical problems Locke applies a mighty argument which goes like this: when we act sinfully, it is assumed that God will punish us. If the offence is serious, it can risk our afterlife. Are we ready to face eternal pain in hell?

This is Locke's balance of pleasure and pain which as an argument is little similar to Blaise Pascal's famous wager (Pénsees, part III, note 233, 1670). Pascal argues that men cannot be sceptical all the way because their existence is limited. They have to suppose that God either exists or he does not. Because human life is vain and wretched, we have nothing to lose by betting on the afterlife. If God does not exist, we lose nothing and if he exists, we can only win (for details, see Hájek 2008).

Locke presents his version of the wager in II, xxi, §70. Although our desires are usually related to immediate pleasures, we have to understand that eternal misery is so powerful a pain that it should be avoided at all costs. Thus we should use our reason and think what is better: all the pleasures in this world or all the misery in the next.

The rewards and punishments of another life, which the Almighty has established, as the enforcements of his law, are of weight enough to determine the Choice, against whatever pleasure and pain this life can shew, when the eternal state is considered but in its bare possibility, which no body can make any 
doubt of (E 281).

Locke's reasoning is different from Pascal's in that he really does not go for the ultimate question God exists and decides our fate, simple as that. Sophisticated estimation of probabilities is also ignored - the crucial issue is only whether the risk is far too great to take or not. Thus the decision is between a virtuous or a sinful life. Locke emphasizes the avoidance of pain which has clearly an Epicurean character. He says:

...though the vertuous life here had nothing but pain, and the vicious continual pleasure...but when infinite happiness is put in one scale, against infinite misery in the other; if the worst, that comes to the pious man, if he mistakes, be the best that the wicked can attain to, if he be in the right, who can without madness run the venture? (E 281-282)

Later in $§ 70$ Locke presents a very similar argument to Pascal’s wager:

...if the good man be in the right, he is eternally happy; if he mistakes, he is not miserable, he feels nothing. On the other side, if the wicked be in the right, he is not happy; if he mistakes, he is infinitely miserable (E 282).

Right at the end of the $\S 70$ Locke alludes to Pascal by saying that it is reasonable to live a virtuous life because in that case we can be certain that there is at least a possibility for a future life. Locke's moral precept is very simple. We put to the one cup of the pair of scales infinite happiness and to the other infinite misery. Independently of our life here in earth, we should think of the afterlife and make sure that there is a chance for infinite happiness. The model of pair of scales Locke applies is traditional, already applied by Homeros and extensively discussed by Professor Dascal in his article ‘The Balance of Reason' (Dascal 2005).

Locke also applies the metaphor of a balance when he discusses the reasons for uneasiness in $§ 57$ of II, xxi. When we contemplate the remote, future good or infinite happiness of the afterlife, we can by willing strongly counterbalance the uneasiness (E 272). There is a constant battle going on between delight and uneasiness. Men's lot is helped in Locke's hypothesis by the fact that all goods are known to man, so we know exactly what to choose in a given situation. The problem for us, admitted by Locke in $\S 60$ is that the future good does not move us or create uneasiness in us - the motive for striving to virtue is only fear of God's punishment in the afterlife. But, as he says in $\S 65$, future pleasure is seldom able to counter-balance any uneasiness, either of pain or desire, which is present (E 277). 
Men can, however, change the pleasantness or unpleasantness that accompanies actions. In $\$ 69$ Locke argues that this can be done by "due consideration in some cases and practice, application and custom in most" (E 280). One can abstain from bread and tobacco at first by reasoning and after a while, by a habit. When one reaches a conclusion that tobacco is not good for one's health, one can remove the pleasure from the act of smoking and after a while, abstinence becomes a habit. Locke argues that a similar procedure concerns virtue. Like drinking a bad-tasting potion for curing an illness and reaching a state of well-being, we can be accustomed to abstain from pleasures to promote our eternal happiness. "But", Locke says, "the pleasure of the action it self is best acquir'd or increased by use and practice." (E 280) Habits can keep us in straight and narrow. For this end, proper education is needed. Locke argues that fashion and the common opinion have settled wrong notions with the result that our values are misplaced. Contrary habits change our pleasures and give relish to that which is necessary or conducive to our happiness.

\section{Leibniz's Critique of Locke's Views}

Theophilus is keen to emphasize the moral hedonism of Philalethes. For example, in $\S 55$, he only cites from Essay the Epicurean dictum "Let us eat and drink...for tomorrow we shall die" (RB 201). On the other hand, he agrees largely with Locke in that there is the present pleasure and the pleasure of the future life: "But if there were only the present, one would have to settle for the perfections which it offered, i. e. for present pleasure" (NE II, xx, §58, RB 202).

But Theophilus is more sceptical than Philalethes in recognizing the good. While the latter applies the example of drinking in $§ 63$, arguing that once we have experienced our first hangover, we would avoid drinking wine, Leibniz typically presents a mathematical example concerning curves which asymptotically approach a straight line in order to argue that a very short time can erase our memory. He discusses blind thoughts, symbols of future happiness and perfection which guide us when we are accustomed to virtue. These moments help us to recollect the virtuous action - in general, our attention is directed towards the present pleasures and pains. "Often one does not so much as raise the question of whether the future good is preferable - one acts solely on impressions, with no thought of bringing them into scrutiny" (RB 203). Like Locke, Leibniz relies on good habits which help us to stay virtuous: “...true happiness requires less knowledge but greater strength and goodness of will, so that the dullest idiot can achieve it just as easily as can the cleverest and most educated person.” (II, xxi, §67, RB 207)

He also agrees with Locke that one can gain new motivation by carefully considering her actions and reflecting whether or not they are good to oneself, as in the case of consuming tobacco (II, xxii, 
$\S 69)$. Thus one can change the pleasantness or unpleasantness of a certain act. When Locke presents his wager in $§ 70$, Leibniz is surprised and happy. He says: "I am very pleased, sir, that you are now correcting the contrary claim you seemed to make before." 3

Perhaps the greatest disagreement between Philalethes and Theophilus in this issue concerns the dichotomy of pleasure and pain. In II, xxi, §64 Locke argues that we cannot enjoy two pleasures at once, much less any pleasure...whilst pain possesses us. It is either pain or pleasure, uneasiness or delight for Locke. Leibniz goes on to give counter-examples: a man with a gout may be overjoyed because a great fortune has come to him and a man living in luxury may be unhappy because of a disgrace at court. To Leibniz, pleasure and pain is a mixture, and joy or sorrow depends upon which components prevail in the mixture (RB 203-204). He even goes on to compare the Lockean man to a little child who chases after the slightest of present sensible pleasure.

In $§ 66$ Locke applies the pair of scales-metaphor and repeats that we should stick to straight and narrow and not take the risk of damnation. While Leibniz certainly agrees with this, he thinks that the balancing in the pair of scales is not sufficient in more complicated decisions (II, xxi, §67). He says that the question of how inevitable a result is cannot be compared with the question of how good or bad it is. This is the problem for casuistry - they make simple comparisons between the probability of a consequence of the moral act and the goodness of the act. Even though an act is good in itself, this does not mean that its consequences are necessarily good. So for Leibniz, one has to think of not only the value of the act itself, but also the consequences which follow from it. When we give a coin to a beggar, we may feel a sense of perfection and a foretaste of the afterlife, but this act, although good in itself, might in the long run lead to consequences which are not necessarily good. Thus simple charity or even inadequate virtue does not necessarily grant us afterlife. In general, in our practical rationality we have to take into account many different aspects, not only employ the pair of scales-model where goodness and badness or pleasure and pain are weighed. Leibniz says:

...in this as in other disparate and heterogeneous assessments with more than one dimension (so to speak), the magnitude of the thing in question is made up proportionately of two estimates; it is like a rectangle with two things to be considered, namely its length and its breadth (II, xxi, §66, RB 206).

Leibniz is a pluralist concerning goods and he can be seen as part of the Aristotelian eudaimonist tradition. One tries to find an optimum where several goods are included in some degree rather than deliberate between the means of reaching one specific good. The model described in the citation above can be called, to follow Simo Knuuttila, a vectorial model of rational decision and it can be 
understood as a functional analysis of different goods which are separate and in competition with each other (Knuuttila 1998). Instead of balancing two options to each other, the moral agent can map different goods (as in co-ordinates) and try to find a balanced optimum between them. In this optimum the goods are not necessarily present maximally, but only to a degree (for details, see Roinila 2007).

\section{Case Study: Akrasia}

To illustrate the differences between the reasoning about the good of the two philosophers, I will conclude my paper with a discussion of akrasia or weakness of the will in II, xxi, §33-35. Locke explains the phenomena by uneasiness. He argues that the will is not necessarily directed to the greatest good, but it is determined by the greatest uneasiness. The greatest good determines the will only in cases when our desire makes us uneasy in the want of it. But it is quite often the case that our desire is directed by less virtuous desires, as Locke notes:

\footnotetext{
...let a drunkard see, that his health decays, his estate wastes; discredit and diseases, and the want of all things, even of his beloved drink, attends him in the course he follows; yet the returns of uneasiness to miss his companions, the habitual thirst after his cups, at the usual time, drives him to the tavern, though he has in his view the loss of health and plenty, and perhaps of the joys of another life... (E II, xxi, §35, 253).
}

A little later Locke relates this case to akrasia.

...thus he is, from time to time, in the state of that unhappy complainer, Video meliora proboque, Deteriora sequoer: ${ }^{4}$ which sentence, allowed for true, and make good by constant experience, may this, and possibly no other, way be easily made intelligible (E II, xxi, §35, 254).

In Locke's view, men strive for virtue, but are frequently hindered by uneasiness which is understood as a strong desire for an absent good, whatever that may be. As the real goods are often weaker to motivate us than sensual goods, we have to work really hard to resist the temptations which lure us continually. In other words, we have to weight the future good with the present goods and decide each time if we are willing to risk the afterlife because of the present real or imagined needs. At most, we can suspend our action to reconsider the reasons and deliberate anew.

Leibniz comments Locke's view extensively in Nouveaux essais. He cannot accept his view that the will is not directed to the greatest good, but does not consider uneasiness necessarily a bad thing 
- there is uneasiness present in some form in all our perceptions. This uneasiness or inquietude (Leibniz's preferred term; the corresponding word in English is disquiet) motivates us to strive for clearer knowledge and keeps us alert at all times. Thus Leibniz sees disquiet as a necessary and mostly positive part of human condition: in addition to clear and distinct ideas, there are always minute, confused perceptions present in our minds which only occasionally become attended and conscious. Because of this, there is seldom only one distinct desire which takes a hold of us. Instead, there are always present numerous spurs to action which may be mutually incompatible. The final volition is more or less a compromise or in an ideal case an optimum between different inclinations:

Various perceptions and inclinations combine to produce a complete volition: it is the result of the conflict amongst them. There are some, imperceptible in themselves, which add up to a disquiet that impels us without our seeing why. There are several that join forces to carry us towards or away from some object, in which case there is desire or fear, also accompanied by a disquiet but not always one amounting to pleasure or displeasure (II, xxi, §39, RB 192).

Leibniz seems to be saying that moral wrong-doing can happen in two ways. In the first case the deliberator is unable to discern the real from the apparent good. The minute perceptions blur our judgement and the disquiet which arises makes us believe that the wrong act is right in a given situation. The apparent good is mistakenly chosen instead of the real good - in other words, the optimization of goods fails because of an error. This is not a case of akrasia, strictly speaking. It is rather the sheer inability (ignorance or error) to discover the real goods in question.

In the second, more serious case, the real good, although it is present and apperceived, is rejected - it does not act as the motivational factor. This kind of case represents acratic action in the true sense for Leibniz (and one can find this strong version also in Locke). The weak-willed agent judges one course of action to involve the greater good, but is inattentive to it, while she is sensitive to the goods involved in the worse course of action (Vailati 1990: 219). These apparent goods are often spiced up by lively sensual qualities, which arise from minute perceptions such as colour, smell, taste and other sensual pleasures. This is why the apparent goods are more desirable to a weak-willed person than the real good which may be less tempting. To use Leibniz's example, a person who perceives the smell of fresh cakes rejects one's diet and gives in to one's desire (II, xxi, $\S 35)$. The real good recommended by the intellect is rejected by the will and the consequent volition is directed to the apparent goods instead of the real good, which may be the second-best alternative. 
turning their thoughts aside, so as to follow their passions. Otherwise we would not find people eating and drinking what they know will make them ill or even kill them (NE I, ii, §11, RB 94).

The difference between Locke and Leibniz is in the way the judgement takes place. According to Locke, we are always conscious of the objects of our will whereas Leibniz argues that we become conscious of them eventually. Thus we may be led to wrong goals due to inattentiveness.

Often the real goods in deliberation, such as virtue, perfection and the afterlife, are present in the form of symbols or blind thoughts, which are faint compared to the more concrete, vivid images of food, drink and sensual pleasures that accompany clear but confused perceptions. However, once the mind is sufficiently developed it becomes sensitive to the real good.

Sometimes they have the idea of an absent good or evil, but only very faintly, so it is no wonder that it has almost no influence on them. Thus, if we prefer the worse it is because we feel the good it contains but not the evil it contains or the good that exists on the opposite side...the finest moral precepts and the best prudential rules in the world have weight only in a soul that is as sensitive to them as to what opposes them (NE II, xxi, §35, RB 186).

This complicated balance of spurs for action illustrate the hypotheses that Leibniz does not have the Lockean model of pair of scales in mind here (although he applies it in many other occasions). In a situation where there are several inclinations to different directions present in the mind, he must have thought it more in terms of the vectorial model explained in the preceding section. The balance of reasons is more complicated in Leibniz's case: it is not for or against, it is more like a dynamical balance as in chemistry or mechanics. Leibniz describes it as follows:

\footnotetext{
Since the final result of the balance is determined by how things weigh against one another, I should think it could happen that the most pressing disquiet did not prevail; for even if it prevailed over each of the contrary endeavours taken singly, it may be outweighed by all of them taken together...everything that then impinges on us weighs in the balance and contributes to determining a resultant direction, almost as in mechanics... (NE II, xxi, §40, RB 193).
}

With the model one can map different inclinations or desires and reflect whether or not they concern apparent or real goods and what possible consequences they may have. Like the pair of scales-model, the vectorial model is a heuristic model, helping us to conceive the options in a given situation. For Leibniz, our moral deliberation is a result of a complicated and dynamical choice between plural goods whereas for Locke it is a question of choosing between good or evil, for future good against risking it. 
Acknowledgements

I would like to thank Professor Marcelo Dascal for inviting me to work in the Leibniz-Lockeproject in the University of Tel Aviv in September-October 2009 and The Academy of Finland and The University of Tel Aviv whose grants made the visit possible. The research done during the period forms the core of this paper. Thanks are also due to the scholars present in the Nordic Workshop of Early Modern Philosophy (Uppsala, Sweden 2010) who commented an earlier version of this paper.

\section{References}

Aaron, R. I. 1955. John Locke. $2^{\text {nd }}$ edition. Oxford: Oxford University Press.

Dascal, M. 2005. The Balance of Reason. In D. Vanderveken (ed.), Logic, Thought and Action. Dordrecht: Springer, pp. 27-47.

Hájek, A. 2008. Pascal's Wager. In E. N. Zalta (ed.), The Stanford

Encyclopedia of Philosophy (Fall 2008 Edition). URL =

<http://plato.stanford.edu/archives/fall2008/entries/pascal-wager/>.

Leibniz, G. W. 1996. New Essays on Human Understanding. Translated and Edited by Peter Remnant and Jonathan Bennett. Cambridge: Cambridge University Press. (RB)

Leibniz, G. W. 1962. Sämtliche Schriften und Briefe, Reihe VI, Band 6. Berlin: Akademie. (A)

Locke, J. 1975. An Essay Concerning Human Understanding. Edited with an Introduction, Critical Apparatus and Glossary by Peter H. Nidditch. Oxford: Oxford University Press. (E)

Knuuttila, S. 1998. Old and New in Leibniz's View of Rational Decision. In S. F. Brown (ed.), Meeting of the Minds. Turnhout, Brepols, pp. 333-346.

Roinila, M. 2007. Leibniz on Rational Decision-Making. University of Helsinki, Helsinki. Thompson, G. 2001. On Locke. Belmont: Wadsworth.

Vailati, E. 1990. Leibniz on Locke on Weakness of Will. Journal of the History of Philosophy 28: 213-228.

\section{Notes}


${ }^{1}$ Page numbers to Locke's and Leibniz's works refer to Nidditch edition of Locke's Essay (1975) (E) and BennettRemnant-edition of Leibniz's New Essays (1996) (RB). The page numbers in the Bennett-Remnant-edition correspond with the Academie-edition of the same work (A VI 6).

${ }^{2}$ What emerges from Locke's scattered remarks is nowhere close to a proper system. However, there are some marks in his Nachlass that he planned to write a systematic work on ethics. Aaron (1955: 256, fn.).

${ }^{3}$ Leibniz refers to E II, xxi, $\$ 55$ where Locke mentions the Epicurean dictum.

4 "I see and approve the better, but follow the worse" (Ovid, Metamorphoses 7.20-21). 